\title{
EVALUASI PELAYANAN ADMINISTRASI TERPADU (PATEN) DENGAN MENGGUNAKAN METODE SERVQUAL SIX SIGMA (STUDI KASUS DI KECAMATAN KURANJI, PADANG)
}

\author{
HESTI YOLANDA, IZZATI RAHMI HG, MAIYASTRI \\ Program Studi Matematika, \\ Fakultas Matematika dan Ilmu Pengetahuan Alam, Universitas Andalas, \\ Kampus UNAND Limau Manis Padang, Indonesia, \\ email : Hestiyolanda115@yahoo.com
}

\begin{abstract}
Abstrak. Pelayanan publik merupakan kegiatan atau rangkaian kegiatan dalam rangka pemenuhan kebutuhan pelayanan bagi setiap warga negara atas barang, jasa dan pelayanan administratif yang disediakan oleh penyelenggara pelayanan publik. Untuk meningkatkan pelayanan publik, pada tahun 2010 melalui Permandagri no 4, pemerintah mengeluarkan pedoman pelayanan administrasi terpadu kecamatan (PATEN). Penelitian ini bertujuan untuk menganalisis tingkat kepuasan masyarakat terhadap PATEN di Kantor Camat Kuranji dan mengevaluasi pelayanan publik di Kantor Camat Kuranji melalui penilaian masyarakat dengan cara menerapkan metode Servqual Six Sigma. Berdasarkan hasil analisis, dapat diketahui bahwa kualitas pelayanan pada Kantor Camat Kuranji belum sesuai dengan kriteria yang ditentukan. Dari analisis proses perhitungan Servqual menunjukkan bahwa masih terdapat indikator-indikator yang belum mencapai target kepuasan, dengan nilai rata-rata tingkat kepuasan yaitu sebesar 80,81406\%, sedangkan dari analisis Six Sigma, diperoleh nilai rata-rata DPMO sebesar 191859,4 dan rata-rata nilai sigma sebesar 2,4. Berdasarkan hasil pengukuran baseline kinerja, terdapat 14 indikator yang berada dibawah nilai rata-rata tingkat kepuasan, nilai rata-rata DPMO dan rata-rata nilai Sigma. Dari 14 indikator tersebut, melalui analisis dengan menggunakan diagram pareto dapat diketahui bahwa indikator yang menjadi prioritas untuk dilakukan perbaikan adalah ruang terbuka hijau yang belum tertata kerapiannya serta area parkir yang belum aman, nyaman dan teratur.
\end{abstract}

Kata Kunci: Pelayanan publik, Servqual, Six Sigma, Baseline kinerja

\section{PENDAHULUAN}

Pelayanan publik merupakan kegiatan atau rangkaian kegiatan dalam rangka pemenuhan kebutuhan pelayanan bagi setiap warga negara atas barang, jasa dan pelayanan administratif yang disediakan oleh penyelenggara pelayanan publik. Adapun upaya pemerintah dalam meningkatkan pelayanan publik yaitu tertera pada Undang-undang Nomor 25 Tahun 2009 pasal 9 ayat (1) ditetapkan bahwa dalam rangka mempermudah pelayanan publik maka diselenggarakanlah sistem pelayanan terpadu. Melalui Permendagri Nomor 4 Tahun 2010, pemerintah mengeluarkan pedoman Pelayanan Administrasi Terpadu Kecamatan (PATEN).

PATEN merupakan inovasi manajemen dalam rangka mendekatkan, mempermudah dan mempercepat pelayanan administrasi perizinan non perizinan di tingkat 
kecamatan, terutama bagi kecamatan yang letaknya jauh dari kantor pemerintah kabupaten/kota dan sulit dijangkau karena faktor kondisi geografis dan infrastruktur jalan yang belum memadai. Pada tanggal 17 Desember 2014 di Kota Padang, Gubernur Sumatera Barat Irwan Prayitno meresmikan peluncuran program penyelenggaraan Pelayanan Administrasi Terpadu Kecamatan (PATEN) pada dua kecamatan yaitu kantor Camat Kuranji dan kantor Camat Pauh.

Agar kualitas dari kinerja PATEN berjalan sesuai dengan yang diinginkan, maka diperlukan peningkatan secara terus-menerus terhadap kinerja PATEN. Salah satu alat ukur yang digunakan untuk mengukur kinerja PATEN adalah dengan menggunakan Metode Servqual Six Sigma. Dalam penelitian ini, akan diteliti bagaimana tingkat kepuasan masyarakat terhadap Pelayanan Administrasi Terpadu Kecamatan (PATEN) untuk mengevaluasi pelayanan publik melalui penilaian masyarakat dengan cara menerapkan metode Servqual Six Sigma.

\section{LANDASAN TEORI}

\subsection{Pelayanan Publik}

Pelayanan publik adalah pemberian pelayanan prima kepada masyarakat yang merupakan perwujudan kewajiban aparatur pemerintah sebagai abdi masyarakat. Untuk mengukur kinerja pelayanan publik berdasarkan penilaian dari pengguna layanan (masyarakat) maka digunakan suatu konsep yaitu metode Servqual (Service quality) [4].

\subsection{Metode Sevgual}

Metode Servqual dibangun atas adanya perbandingan dua faktor utama yaitu persepsi pelanggan atas layanan nyata yang diterima (perceived service) dengan layanan yang sesungguhnya diharapkan oleh pelanggan (expected service). Metode Servqual membagi kualitas pelayanan kedalam lima dimensi sebagai berikut.

(1) Tangible (Bukti fisik), yaitu kemampuan suatu perusahaan dalam menunjukkan eksistensinya pada pihak eksternal.

(2) Reliability (Keandalan), yaitu kemampuan untuk memberikan layanan yang sesuai dengan dijanjikan, akurat, tepat waktu, memuaskan dan dapat dipercaya.

(3) Responsiveness (Daya tanggap), yaitu kemampuan dan kesiapan para karyawan untuk membantu para pelanggan dan memberikan pelayanan dengan tanggap.

(4) Assurance (jaminan), yaitu mencakup kemampuan pengetahuan, kesopanan dan sifat dapat dipercaya oleh pelanggan yang dimiliki oleh para karyawan, sehingga dapat meyakinkan pelanggan mengenai kualitas layanan yang diberikan.

(5) Emphaty (empati), yaitu berusaha untuk mengetahui dan mengerti kebutuhan pelanggan dengan memberikan komunikasi yang baik, sikap peduli dan perhatian kepada pelanggan. 


\subsection{Metode Six Siqma}

Six Sigma didefinisikan sebagai metode peningkatan proses bisnis yang bertujuan untuk menemukan dan mengurangi faktor-faktor penyebab kecacatan dan kesalahan, mengurangi waktu siklus, biaya operasi, meningkatkan produktivitas dan memenuhi kebutuhan pelanggan dengan lebih baik [4]. Dalam produksi, standar Six sigma dikenal istilah defectively rate of the process dengan nilai 3.4 defect di setiap juta unit/proses. Artinya dalam satu juta unit/proses hanya diperkenankan mengalami kegagalan/cacat produk sebanyak 3.4 unit/proses.

Terdapat lima tahapan dalam Six Sigma yang dikenal dengan DMAIC yaitu Define, Measure, Analyze, Improve, dan Control. DMAIC digunakan sebagai problem solving dalam melakukan perbaikan. Masing-masing tahapan dapat dijelaskan sebagai berikut.

(a) Define, merupakan langkah awal dalam pendekatan Six Sigma. Define merupakan tahap mengindentifikasi masalah penting dalam suatu proses yang sedang berlangsung.

(b) Measure, merupakan langkah kedua dalam metode peningkatan kualitas Six Sigma. Peningkatan kualitas akan terfokus pada upaya-upaya yang giat dalam peningkatan kualitas menuju kegagalan nol (zero defect) sehingga memberikan kepuasan total kepada pelanggan. Maka sebelum peningkatan kualitas dengan Six Sigma dimulai, terlebih dahulu harus diketahui tingkat kinerja saat ini (baseline kinerja). Baseline kinerja dalam Six Sigma dapat ditentukan dengan menggunakan suatu pengukuran DPMO (Defect Per Million Opportunities) dan tingkat sigma (sigma level) pada tiap indikator. Persamaan yang digunakan adalah sebagai berikut.

(1) Tingkat kepuasan sekarang diperoleh dengan cara:

$$
\text { Target kepuasan }=\left(\frac{\text { Rata-rata tingkat persepsi }}{\text { Target kepuasan }}\right) \times 100 \%
$$

(2) Menghitung DPMO.

$$
\mathrm{DPMO}=\left[1-\left(\frac{\text { Rata-rata tingkat persepsi }}{\text { Target Kepuasan }}\right)\right] \times 1.000 .000
$$

(3) Perhitungan Nilai Sigma.

$$
\text { Nilai Sigma }=\text { normsinv }\left(1-\frac{D P M O}{1.000 .000}\right)+1,5 \text {. }
$$

(c) Analyze, yang merupakan tahap untuk menentukan faktor-faktor yang paling mempengaruhi proses artinya mencari satu atau dua faktor yang jika diperbaiki akan memperbaiki proses secara dramatis [4]. Untuk mengidentifikasi penyebab kegagalan/kecacatan dapat digunakan diagram sebab akibat atau sering disebut diagram fishbone atau Ishikawa.

(d) Improve, merupakan tahapan pembuatan rancangan solusi dalam melakukan perbaikan Six Sigma pada proses-proses yang memerlukan perbaikan. Rancangan berupa usulan perbaikan kualitas bagi setiap indikator potensial, sehingga diharapkan dapat meningkatkan performansi kualitas yang dihasilkan oleh proses. 
(e) Control, merupakan tahapan untuk melakukan perbaikan secara terus menerus, agar proses tetap terkontrol dan mencegah agar tidak terjadi kecacatan terhadap proses. Pada tahap Servqual dengan mengitung nilai gap untuk setiap indikator yang diukur/diamati merupakan selisih antara $\bar{X}_{i}$ dengan $\bar{Y}_{i}$.

Diagram Pareto digunakan untuk menentukan faktor yang paling berpengaruh terhadap suatu kejadian atau proses [4]. Sementara diagram sebab akibat digunakan untuk mengorganisasikan informasi hasil diskusi/brainstorming sebab-sebab suatu masalah [9].

\section{PEMBAHASAN}

Data yang dianalisis merupakan data sampel yang diambil dengan cara melakukan penyebaran kuesioner di Kantor Camat Kuranji sebanyak 169 kuesioner. Pada perhitungan Servqual ini akan dilakukan analisis tingkat kepuasan, yaitu dengan cara menghitung gap/kesenjangan antara nilai rata-rata persepsi/kinerja dengan nilai rata-rata harapan/kepentingan. Berikut rangkuman hasil perhitungan nilai tingkat persepsi/kinerja, nilai tingkat harapan/kepentingan, nilai rata-rata persepsi/kinerja, nilai rata-rata harapan/kepentingan dan gap yang dapat dilihat pada Tabel 1.

Tabel 1. Hasil Perhitungan Tingkat Persepsi/kinerja, Tingkat Harapan/kepentingan, Nilai Ratarara Persepsi/kinerja, Nilai Rata-rata Harapan/kepentingan, Gap

\begin{tabular}{|c|c|c|c|c|c|c|}
\hline No & Indikator & $X$ & $Y$ & $\bar{X}_{i}$ & $\bar{Y}_{i}$ & Gap \\
\hline 1 & Ruang tunggu yang nyaman & 744 & 764 & 4,402367 & 4,520710 & $-0,12$ \\
\hline 2 & Kantor enak dilihat atau dipandang & 715 & 746 & 4,230769 & 4,414201 & $-0,18$ \\
\hline 3 & Terdapat tempat piket yang representatif $\left(T_{3}\right)$ & 724 & 755 & 4,284024 & 4,467456 & $-0,18$ \\
\hline 4 & $\begin{array}{l}\text { Terdapat loket/meja yang difungsikan } \\
\text { khusus untuk pelayanan }\end{array}$ & 721 & 764 & 4,266272 & 4,520710 & $-0,25$ \\
\hline 5 & $\begin{array}{l}\text { Memiliki lapangan parkir } \\
\text { yang cukup luas }\end{array}$ & 673 & 703 & 3,982248 & 4,159763 & $-0,18$ \\
\hline 6 & Kantor bersih dan tertata rapi & 720 & 740 & 4,260355 & 4,378698 & $-0,12$ \\
\hline 7 & $\begin{array}{l}\text { Penempatan papan informasi/ } \\
\text { pengumuman yang mudah dilihat }\end{array}$ & 683 & 764 & 4,041420 & 4,520710 & $-0,48$ \\
\hline 8 & $\begin{array}{l}\text { Petunjuk papan informasi/ } \\
\text { pengumuman mudah dipahami }\end{array}$ & 696 & 755 & 4,118343 & 4,467456 & $-0,35$ \\
\hline 9 & Terdapat ruang terbuka hijau & 408 & 625 & 2,414201 & 3,698225 & $-1,28$ \\
\hline 10 & Memiliki toilet yang bersih & 692 & 744 & 4,094674 & 4,402367 & $-0,31$ \\
\hline 11 & Jam pelayanan yang tepat waktu & 714 & 796 & 4,224852 & 4,710059 & $-0,48$ \\
\hline 12 & $\begin{array}{l}\text { Menggunakan system FIFO } \\
\text { (First In First Out) }\end{array}$ & 727 & 773 & 4,301775 & 4,573965 & $-0,27$ \\
\hline 13 & $\begin{array}{l}\text { Kecepatan pegawai dalam } \\
\text { melayani masyarakat }\end{array}$ & 669 & 763 & 3,958580 & 4,514793 & $-0,56$ \\
\hline 14 & $\begin{array}{l}\text { Ketepatan pegawai dalam } \\
\text { melayani masyarakat }\end{array}$ & 675 & 747 & 3,994083 & 4,420118 & $-0,43$ \\
\hline
\end{tabular}




\begin{tabular}{|c|c|c|c|c|c|c|}
\hline No & Indikator & $X$ & $Y$ & $\bar{X}_{i}$ & $\bar{Y}_{i}$ & Gap \\
\hline 15 & $\begin{array}{l}\text { Persyaratan administrasi yang jelas } \\
\text { dan sesuai dengan pelayanan } \\
\text { yang dibutuhkan }\end{array}$ & 704 & 744 & 4,165680 & 4,402367 & $-0,24$ \\
\hline 16 & $\begin{array}{l}\text { Prosedur atau proses pelayanan } \\
\text { yang mudah dipahami }\end{array}$ & 689 & 746 & 4,076923 & 4,414201 & $-0,34$ \\
\hline 17 & $\begin{array}{l}\text { Biaya administrasi sesuai dengan } \\
\text { yang seharusnya }\end{array}$ & 715 & 733 & 4,230769 & 4,337278 & $-0,11$ \\
\hline 18 & $\begin{array}{l}\text { Teratasinya setiap keluhan masyarakat } \\
\text { oleh petugas pelayanan atau pegawai }\end{array}$ & 675 & 724 & 3,994083 & 4,284024 & $-0,29$ \\
\hline 19 & $\begin{array}{l}\text { Tidak adanya kesulitan masyarakat } \\
\text { dalam melaporkan masalah }\end{array}$ & 678 & 732 & 4,011834 & 4,331361 & $-0,32$ \\
\hline 20 & $\begin{array}{l}\text { Kesigapan pegawai atau petugas layanan } \\
\text { dalam merespon masyarakat }\end{array}$ & 683 & 742 & 4,041420 & 4,390532 & $-0,35$ \\
\hline 21 & $\begin{array}{l}\text { Petugas tidak bertele-tele } \\
\text { dalam menyelesaikan masalah }\end{array}$ & 667 & 747 & 3,946746 & 4,420118 & $-0,47$ \\
\hline 22 & Cepat dalam mengatasi masalah & 675 & 770 & 3,994083 & 4,556213 & $-0,56$ \\
\hline 23 & $\begin{array}{l}\text { Petugas atau pegawai mampu menjawab } \\
\text { setiap pertanyaaan yang diajukan }\end{array}$ & 678 & 722 & 4,011834 & 4,272189 & $-0,26$ \\
\hline 24 & Selalu ada pegawai disetiap jam kerja & 706 & 792 & 4,177515 & 4,686390 & $-0,51$ \\
\hline 25 & Pelayanan yang sopan dan ramah & 704 & 780 & 4,165680 & 4,615385 & $-0,45$ \\
\hline 26 & Setiap dokumen dicek dan diteliti petugas & 719 & 784 & 4,254438 & 4,639053 & $-0,38$ \\
\hline 27 & Area parkir yang aman, nyaman dan teratur & 561 & 699 & 3,319527 & 4,136095 & $-0,82$ \\
\hline 28 & $\begin{array}{l}\text { Tidak adanya pungutan biaya } \\
\text { terhadap lahan parkir }\end{array}$ & 727 & 739 & 4,301775 & 4,372781 & $-0,07$ \\
\hline 29 & $\begin{array}{l}\text { Perhatian pegawai pada setiap } \\
\text { individu masyarakat yang melapor }\end{array}$ & 679 & 685 & 4,017751 & 4,053254 & $-0,03$ \\
\hline 30 & $\begin{array}{l}\text { Selalu ada pegawai yang membantu } \\
\text { pada setiap masalah/kasus yang } \\
\text { disampaikan oleh masyarakat }\end{array}$ & 678 & 729 & 4,011834 & 4,313609 & $-0,30$ \\
\hline 31 & $\begin{array}{l}\text { Informasi disampaikan dengan } \\
\text { jelas dan mudah dipahami oleh masyarakat }\end{array}$ & 697 & 740 & 4,124260 & 4,378698 & $-0,25$ \\
\hline 32 & $\begin{array}{l}\text { Pegawai tidak memandang status } \\
\text { sosial pada setiap pelayanan }\end{array}$ & 678 & 693 & 4,011834 & 4,100592 & $-0,09$ \\
\hline 33 & $\begin{array}{l}\text { Terjalin komunikasi yang baik } \\
\text { antar pegawai dengan masyarakat }\end{array}$ & 661 & 710 & 3,911243 & 4,201183 & $-0,29$ \\
\hline
\end{tabular}

Keterangan.

$$
\begin{aligned}
& X: \text { Tingkat Persepsi/kinerja } \\
& Y: \text { Tingkat harapan/kepentingan } \\
& \bar{X}_{i}: \text { Rata-rata tingkat Persepsi/kinerja } \\
& \bar{Y}_{i}: \text { Rata-rata tingkat harapan/kepentingan }
\end{aligned}
$$

\subsection{Tahapan Six Sigma}

\section{Define}

Dalam hasil perhitungan pada tahap Servqual, yaitu berdasarkan Tabel 1, terlihat bahwa yang memiliki gap/kesenjangan paling besar adalah pada indikator $T_{9}$ 
yakni Terdapatnya ruang terbuka hijau, dengan gap/kesenjangan antara persepsi dan harapan masyarakat sebesar $-1,28$. Selanjutnya, indikator yang memiliki nilai gap/kesenjangan terbesar setelah indikator $T_{9}$ adalah indikator $A_{4}$ yaitu Area parkir yang aman, nyaman dan teratur, dengan gap/kesenjangan antara persepsi dan harapan masyarakat sebesar -0, 82. Masalah ini bisa menimbulkan rasa kenyamanan masyarakat yang kurang baik terhadap Kantor Camat Kuranji. Namun agar lebih pasti maka selanjutnya harus dilakukan tahap Six Sigma untuk melihat masalah kritis lainnya.

\section{Measure}

Tahap Measure dimulai dengan cara menghitung tingkat kepuasan, DPMO, dan nilai sigma untuk mengetahui proses yang berjalan berada pada beberapa tingkat sigma. Pada penelitian ini target kepuasan yang ingin dicapai adalah skor 5 yaitu sangat puas berasal dari jawaban skala Likert kepuasan dari angka 1 yaitu tidak puas sampai angka 5 yakni sangat puas. Sehingga dari hasil pengukuran DPMO dan tingkat sigma pada tiap indikator diperoleh baseline kinerja dalam Six Sigma seperti yang terlihat pada Tabel 2 .

Tabel 2. Hasil Pengukuran Baseline Kinerja Berdasarkan Indikator

\begin{tabular}{|l|c|c|c|c|c|c|c|c|}
\hline No & Dimensi & $\bar{X}_{i}$ & $\bar{Y}_{i}$ & Gap & $\begin{array}{c}\text { Target } \\
\text { Kepuasan }\end{array}$ & $\begin{array}{c}\text { Tingkat } \\
\text { Kepuasan }\end{array}$ & DPMO & Sigma \\
\hline 1 & T1 & 4,402367 & 4,520710 & $-0,12$ & 5 & $88,04734 \%$ & 119526,6 & 2,7 \\
\hline 2 & T2 & 4,230769 & 4,414201 & $-0,18$ & 5 & $84,61538 \%$ & 153846,1 & 2,5 \\
\hline 3 & T3 & 4,284024 & 4,467456 & $-0,18$ & 5 & $85,68047 \%$ & 143195,3 & 2,6 \\
\hline 4 & T4 & 4,266272 & 4,520710 & $-0,25$ & 5 & $85,32544 \%$ & 146745,6 & 2,5 \\
\hline 5 & T5 & 3,982248 & 4,159763 & $-0,18$ & 5 & $79,64497 \%$ & 203550,3 & 2,3 \\
\hline 6 & T6 & 4,260355 & 4,378698 & $-0,12$ & 5 & $85,20710 \%$ & 147929,0 & 2,5 \\
\hline 7 & T7 & 4,041420 & 4,520710 & $-0,48$ & 5 & $80,82840 \%$ & 191716,0 & 2,4 \\
\hline 8 & T8 & 4,118343 & 4,467456 & $-0,35$ & 5 & $82,36686 \%$ & 176331,4 & 2,4 \\
\hline 9 & T9 & 2,414201 & 3,698225 & $-1,28$ & 5 & $48,28402 \%$ & 517159,8 & 1,4 \\
\hline 10 & T10 & 4,094674 & 4,402367 & $-0,31$ & 5 & $81,89349 \%$ & 181065,1 & 2,4 \\
\hline 11 & Rl1 & 4,224852 & 4,710059 & $-0,48$ & 5 & $84,49704 \%$ & 155029,6 & 2,5 \\
\hline 12 & Rl2 & 4,301775 & 4,573965 & $-0,27$ & 5 & $86,03550 \%$ & 139645,0 & 2,6 \\
\hline 13 & Rl3 & 3,958580 & 4,514793 & $-0,56$ & 5 & $79,17160 \%$ & 208284,0 & 2,3 \\
\hline 14 & Rl4 & 3,994083 & 4,420118 & $-0,43$ & 5 & $79,88166 \%$ & 201183,4 & 2,3 \\
\hline 15 & Rl5 & 4,165680 & 4,402367 & $-0,24$ & 5 & $83,31361 \%$ & 166863,9 & 2,5 \\
\hline 16 & Rl6 & 4,076923 & 4,414201 & $-0,34$ & 5 & $81,53885 \%$ & 184615,4 & 2,4 \\
\hline 17 & Rl7 & 4,230769 & 4,337278 & $-0,11$ & 5 & $84,61538 \%$ & 153846,1 & 2,5 \\
\hline 18 & Rs1 & 3,994083 & 4,284024 & $-0,29$ & 5 & $79,88166 \%$ & 201183,4 & 2,3 \\
\hline 19 & Rs2 & 4,011834 & 4,331361 & $-0,32$ & 5 & $80,23669 \%$ & 197633,1 & 2,3 \\
\hline 20 & Rs3 & 4,041420 & 4,390532 & $-0,35$ & 5 & $80,82840 \%$ & 191716,0 & 2,4 \\
\hline 21 & Rs4 & 3,946746 & 4,420118 & $-0,47$ & 5 & $78,93491 \%$ & 210651,0 & 2,3 \\
\hline 22 & Rs5 & 3,994083 & 4,556213 & $-0,56$ & 5 & $79,88166 \%$ & 201183,4 & 2,3 \\
\hline 23 & Rs6 & 4,011834 & 4,272189 & $-0,26$ & 5 & $80,23669 \%$ & 197633,1 & 2,3 \\
\hline 24 & A1 & 4,177515 & 4,686390 & $-0,51$ & 5 & $83,55030 \%$ & 164497,0 & 2,5 \\
\hline
\end{tabular}




\begin{tabular}{|c|c|c|c|c|c|c|c|c|}
\hline No & Dimensi & $\bar{X}_{i}$ & $\bar{Y}_{i}$ & Gap & $\begin{array}{c}\text { Target } \\
\text { Kepuasan }\end{array}$ & $\begin{array}{c}\text { Tingkat } \\
\text { Kepuasan }\end{array}$ & DPMO & Sigma \\
\hline 25 & A2 & 4,165680 & 4,615385 & $-0,45$ & 5 & $83,31361 \%$ & 166863,9 & 2,5 \\
\hline 26 & A3 & 4,254438 & 4,639053 & $-0,38$ & 5 & $85,08876 \%$ & 149112,4 & 2,5 \\
\hline 27 & A4 & 3,319527 & 4,136095 & $-0,82$ & 5 & $66,39053 \%$ & 336094,7 & 1,9 \\
\hline 28 & A5 & 4,301775 & 4,372781 & $-0,07$ & 5 & $86,03550 \%$ & 139645,0 & 2,6 \\
\hline 29 & E1 & 4,017751 & 4,053254 & $-0,03$ & 5 & $80,35503 \%$ & 196449,7 & 2,3 \\
\hline 30 & E2 & 4,011834 & 4,313609 & $-0,30$ & 5 & $80,23669 \%$ & 197633,1 & 2,3 \\
\hline 31 & E3 & 4,124260 & 4,378698 & $-0,25$ & 5 & $82,48521 \%$ & 175147,9 & 2,4 \\
\hline 32 & E4 & 4,011834 & 4,100592 & $-0,09$ & 5 & $80,23669 \%$ & 197633,1 & 2,3 \\
\hline 33 & E5 & 3,911243 & 4,201183 & $-0,29$ & 5 & $78,22485 \%$ & 217751,5 & 2,3 \\
\hline \multicolumn{2}{|c|}{ Rata-rata } & 4,040703 & 4,384077 & $-0,34$ & 5 & $80,81406 \%$ & 191859,4 & 2,4 \\
\hline
\end{tabular}

\section{Analyze}

Dari hasil perhitungan nilai sigma, dapat dilihat bahwa terdapat indikator-indikator yang memiliki nilai sigma dibawah rata-rata. Berdasarkan hasil perhitungan dari nilai rata-rata sigma pada Tabel 2, dapat dilihat bahwa terdapat 14 indikator pelayanan yang berada dibawah nilai rata-rata sigma, seperti pada Tabel 3 .

Selanjutnya akan dilakukan analisis dengan menggunakan diagram pareto untuk mengetahui tingkat DPMO paling besar atau paling tinggi yang menimbulkan ketidakpuasan masyarakat terhadap pelayanan atau fasilitas yang diberikan, seperti dalam Gambar 1.

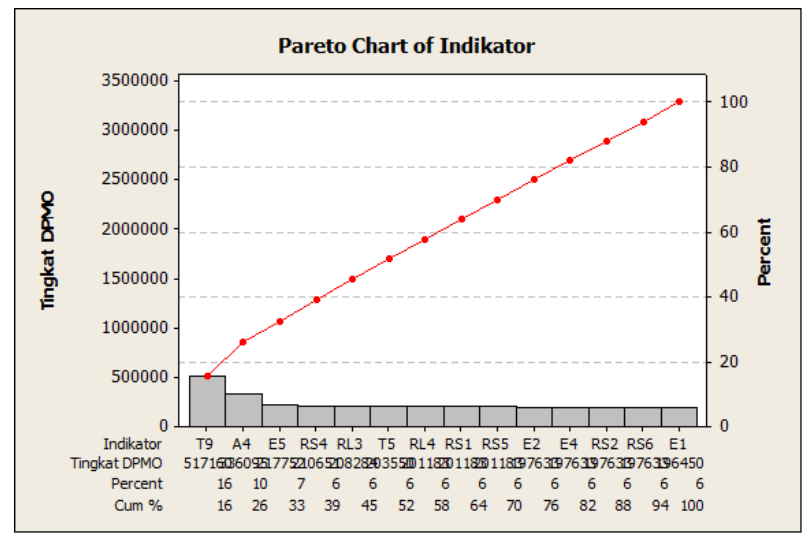

Gambar 1. Diagram pareto tingkat DPMO masyarakat yang datang ke Kantor Camat Kuranji

Dari diagram pareto diatas terlihat bahwa yang memiliki tingkat ketidakpuasan paling tinggi ialah indikator $T_{9}$ dan diikuiti dengan indikator $A_{4}$, kedua indikator tersebut terlihat mendominasi jika dibandingkan dengan indikator-indikator lainnya. Hal ini jika dibiarkan bisa berakibat buruk terhadap kualitas pelayanan, dikarenakan menimbulkan rasa kenyamanan masyarakat yang kurang baik terhadap 
Tabel 3. Penentuan indikator yang harus dianalisis

\begin{tabular}{|c|c|c|c|}
\hline No & Indikator & DPMO & Nilai Sigma \\
\hline 1 & Memiliki lapangan parkir yang cukup luas & 203550,3 & 2,3 \\
\hline 2 & Terdapatnya ruang terbuka hijau & 517159,8 & 1,4 \\
\hline 3 & $\begin{array}{l}\text { Kecepatan pegawai dalam } \\
\text { melayani masyarakat }\end{array}$ & 208284,0 & 2,3 \\
\hline 4 & $\begin{array}{l}\text { Ketepatan pegawai dalam } \\
\text { melayani masyarakat }\end{array}$ & 201183,4 & 2,3 \\
\hline 5 & $\begin{array}{l}\text { Teratasinya setiap keluhan masyarakat } \\
\text { oleh petugas pelayanan atau pegawai }\end{array}$ & 201183,4 & 2,3 \\
\hline 6 & $\begin{array}{l}\text { Tidak adanya kesulitan masyarakat } \\
\text { dalam melaporkan masalah }\end{array}$ & 197633,1 & 2,3 \\
\hline 7 & $\begin{array}{l}\text { Petugas tidak bertele-tele } \\
\text { dalam menyelesaikan masalah }\end{array}$ & 210651,0 & 2,3 \\
\hline 8 & Cepat dalam mengatasi masalah & 201183,4 & 2,3 \\
\hline 9 & $\begin{array}{l}\text { Petugas atau pegawai mampu menjawab } \\
\text { setiap pertanyaaan yang diajukan }\end{array}$ & 197633,1 & 2,3 \\
\hline 10 & Area parkir yang aman, nyaman dan teratur & 336094,7 & 1,9 \\
\hline 11 & $\begin{array}{l}\text { Perhatian pegawai pada } \\
\text { individu masyarakat yang melapor }\end{array}$ & 196449,7 & 2,3 \\
\hline 12 & $\begin{array}{l}\text { Selalu ada pegawai yang membantu } \\
\text { pada setiap masalah/kasus yang } \\
\text { disampaikan oleh masyarakat }\end{array}$ & 197633,1 & 2,3 \\
\hline 13 & $\begin{array}{l}\text { Pegawai tidak memandang status } \\
\text { sosial pada setiap pelayanan }\end{array}$ & 197633,1 & 2,3 \\
\hline 14 & $\begin{array}{l}\text { Terjalin komunikasi yang baik } \\
\text { antar pegawai dengan masyarakat }\end{array}$ & 217751,5 & 2,3 \\
\hline
\end{tabular}

pelayanan di Kantor Camat Kuranji. Oleh karena itu, langkah selanjutya ialah melakukan pemecahan masalah dengan cara membuat diagram sebab akibat ( fishbone diagram) seperti yang terlihat pada Gambar 2.

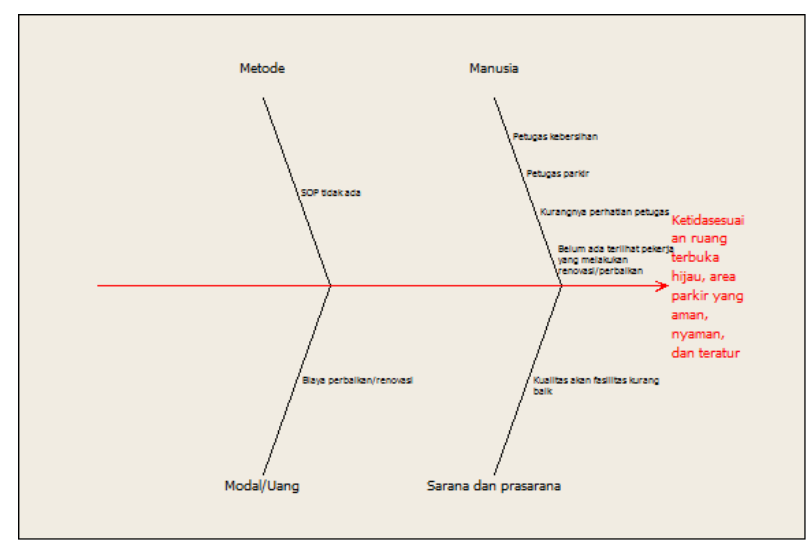

Gambar 2. Diagram sebab akibat ketidaksesuaian ruang terbuka hijau, area parkir yang aman, nyaman, dan teratur 


\section{Improve}

Tahap Improve merupakan tahap perbaikan dengan membuat rancangan solusi dalam melakukan perbaikan, dan peningkatan kualitas Six Sigma pada prosesproses yang memerlukan perbaikan.

(a) Manusia.

Usulan agar ruang terbuka hijau menjadi lebih baik, maka diperlukan perhatian lebih dengan adanya petugas yang bertanggung jawab dalam merawat ruang terbuka hijau tersebut dan diperlukan petugas parkir agar area parkir menjadi aman dan teratur, sehingga masyarakat merasa aman dan nyaman.

(b) Metode.

Usulan untuk mengatasi tidak adanya standar adalah dengan membuat SOP serta diperlukan adanya komitmen dari pegawai dan manajemen untuk menerapkan SOP.

(c) Modal/Uang.

Usulan agar ruangan terbuka hijau tertata menjadi lebih baik dan area parkir menjadi lebih baik adalah dengan adanya pendanaan dari pihak pemerintah untuk memperbaiki atau merenovasi fasilitas tersebut.

(d) Sarana dan Prasarana.

Usulan untuk mengatasi ruang terbuka hijau dan lahan parkir menjadi lebih baik adalah dengan dilakukannya perbaikan/renovasi.

\section{Control}

Tahap Control tidak dapat dilakukan oleh peneliti dikarenakan tahap ini membutuhkan waktu yang lama karena control ini harus dilakukan secara terus menerus, sementara peneliti memiliki waktu yang terbatas.

\section{Kesimpulan}

Berdasarkan hasil evaluasi pelayanan paten dengan menggunakan metode Servqual Six Sigma didapat hasil kesimpulan sebagai berikut.

(1) Dari analisis proses perhitungan Servqual menunjukkan bahwa masih banyak indikator-indikator yang belum mencapai target kepuasan. Hal ini terlihat pada gap/kesenjangan yang bernilai kurang dari nol $(<0)$ yaitu menunjukkan bahwa adanya kesenjangan antara harapan dan persepsi masyarakat yang menerima pelayanan di Kantor Camat Kuranji.

(2) Berdasarkan perolehan hasil pengukuran baseline kinerja terdapat 14 indikator yang berada dibawah rata-rata tingkat kepuasan yaitu sebesar $80,81406 \%$ dengan nilai rata-rata DPMO sebesar 191859,4 dan rata-rata nilai sigma sebesar 2,4 .

(3) Berdasarkan perolehan hasil pengukuran baseline kinerja dan melalui diagram pareto, indikator yang menjadi prioritas untuk dilakukan perbaikan adalah ruang terbuka hijau yang belum tertata kerapiannya serta area parkir yang belum aman, belum nyaman, dan belum teratur. 


\section{Daftar Pustaka}

[1] Besterfield, D. H. 1998. Quality Control. Prentice-Hall, Inc, New Jersey.

[2] Darwati, dkk. 2015. Pendekatan Servqual Lean Six Sigma Menggunakan Diagram Kontrol Hotelling Untuk Meningkatkan Kualitas Pelayanan Pendidikan (Studi Kasus di Jurusan Statistika Universitas Diponegoro). Jurnal Gaussian 4(2) : $305-314$

[3] Firdian, dkk. 2012. Aplikasi Metode Servqual Six dan Six Sigma Dalam Menganalisis Kualitas Layanan PT. PLN (Persero) Unit Pelayanan Jaringan (UPJ) Dinoyo Malang. Jurnal IPREKAS 13(3) : Hal 1412 - 1437.

[4] Manggala, D. 2005. Mengenal Six Sigma secara sederhana, http://beranda.net

[5] Montgomery, D.C. 2009. Statistical Quality Control : A Modern Introduction. Sixth Ed. International Student Version. Arizona

[6] Sarwono, J. 2006. Analisis Data Penelitian Menggunakan SPSS. Andi, Yogyakarta

[7] Siregar, S. 2010. Statistika Deskriptif Untuk Data Penelitian. Dilengkapi Perhitungan Manual Dan Aplikasi SPSS Versi 17. Rajawali Pers, Jakarta.

[8] Sugiyono. 2009. Metode Penelitian Bisnis. Alfabeta, Bandung

[9] Trihendri, C. 2006. Statistik SIX SIGMA dengan Minitab. Pandu Cerdas Inisiatif Kualitas. ANDI

[10] Usman, dkk. 2003. Pengantar Statistika. Bumi Aksara, Jakarta.

[11] Utomo, Sad Dian. 2010. Kebijakan Pelayanan Administrasi Terpadu Kecamatan (PATEN). Direktorat Jenderal Pemerintahan Umum Kementrian Dalam Negeri Republik Indonesia. 